\title{
Implicações da perspectiva de Wertsch para a inter- pretação da teoria de Vygotsky no ensino de Física ${ }^{+*}$
}

\author{
Alexsandro Pereira de Pereira \\ Paulo Lima Junior \\ Instituto de Física - UFRGS \\ Porto Alegre - RS
}

\section{Resumo}

No presente trabalho, apresentamos uma introdução às ideias de Vygotsky a partir da perspectiva do psicólogo norte-americano James $V$. Wertsch. São destacados três temas centrais na obra de Vygotsky: (1) mediação; (2) interação social; e (3) desenvolvimento. Este trabalho é motivado por alguns equívocos de interpretação tipicamente encontrados na literatura, tais como: interação social como negociação de significados; professor como mediador do conhecimento; livro didático como parceiro mais capaz; desenvolvimento como construção de novas estruturas cognitivas. Implicações dessa perspectiva para o ensino e a pesquisa em ensino de Física são discutidas.

Palavras-chave: Vygotsky. Ensino de Física.

\begin{abstract}
In this paper, we introduce Vygotsky's ideas from the perspective of the American psychologist James V. Wertsch. We highlight three basic themes in Vygotsky's writings: (1) mediation; (2) social
\end{abstract}

\footnotetext{
+ Implications of Wertschian perspective for the interpretation of Vygotsky's theory in Physics teaching

* Recebido: outubro de 2013. Aceito: maio de 2014.
} 
interaction; and (3) development. This study is motivated by some misinterpretations typically found in the literature, such as: social interaction as negotiation of meanings; teacher as knowledge mediator; textbook as more capable peer; development as the construction of new cognitive structures. Implications of this perspective for teaching and research in Physics teaching are discussed.

Keywords: Vygotsky. Teaching of Physics.

\section{Introdução}

Vygotsky, assim como Piaget, é considerado um dos nomes mais importantes da psicologia do desenvolvimento. No ensino de Física, a teoria de Vygotsky tem servido como aporte teórico para diversos projetos de pesquisa e de desenvolvimento. $\mathrm{O}$ presente texto pretende discutir alguns problemas de interpretação relativos à teoria de Vygotsky encontrados em artigos de ensino de Física. Optou-se por não fazer críticas diretas a trabalhos já publicados para não desmerecer a importância de autores pioneiros na abordagem vygotskiana, que trouxeram importantes contribuições para o ensino de Física. O objetivo central deste artigo é ajudar o leitor interessado em implicações práticas da teoria de Vygotsky a evitar certos erros básicos e a apreciar o brilhantismo das ideias radicalmente novas desse autor. Conforme veremos nas próximas páginas, esta nova leitura da teoria vygotskiana traz diferentes contribuições para o ensino de Física, para além das comumente divulgadas.

Após discutir sobre os principais equívocos da teoria vygotskiana no Brasil, esboçaremos uma introdução às ideias de Lev S. Vygotsky a partir da perspectiva do psicólogo norte-americano James V. Wertsch $(1985,1991)$. Nos anos 70, Wertsch realizou um ano de pós-doutorado em Moscou, onde trabalhou em colaboração com ilustres ex-colegas de Vygotsky, tais como A. R. Luria e A. N. Leonti$\mathrm{ev}^{1}$.

${ }^{1}$ É importante destacar que existe uma disputa sobre a herança intelectual de Vygotsky, representada, de um lado, pela teoria histórico-cultural e, de outro, pela teoria da atividade (ZINCHENKO, 1998). Dois importantes proponentes dessas duas vertentes na atualidade são James Wertsch (1985, 1991) e Yrjö Engeström (1999), respectivamente. 
É importante destacar que as ideias discutidas neste artigo já são bastante difundidas entre pesquisadores que adotam uma perspectiva sociocultural do ensino de ciências e, portanto, não apresentam novidade alguma. No entanto, tendo em vista a forte "tradição cognitivista" dentro da qual os profissionais do ensino de Física são formados, falta ainda na literatura um artigo alertando sobre os principais problemas conceituais que uma leitura "apressada" da teoria vygotskiana pode levar. O presente artigo pretende preencher essa lacuna.

\section{Os problemas de interpretação da teoria vygotskiana}

Com a ênfase nos estudos a partir da fundamentação sociocultural, ocorrida na área de pesquisa em ensino de ciência, iniciada, no Brasil, em meados dos anos 90, diversos pesquisadores da área passaram a buscar quadros teóricos alternativos, que privilegiassem o papel da linguagem e das relações sociais no processo de ensino/aprendizagem em detrimento da análise de estruturas cognitivas do aprendiz. Nesse sentido, a teoria de Vygotsky tem se tornado foco de um renovado interesse nas pesquisas em ensino de ciências. A recente publicação (e republicação) de textos originais com tradução para o inglês e a vinda, para o Ocidente, de vários psicólogos soviéticos capazes de lidar com esses textos com autoridade (WERTSCH; TULVISTE, 1992) têm revelado que muitas das ideias de Vygotsky não são amplamente compartilhadas, ou até mesmo compreendidas, no cenário da psicologia contemporânea (WERTSCH, 1991) $)^{2}$.

Para alguns autores, a pobre tradução e edição dos textos de Vygotsky para o inglês têm contribuído para diferentes interpretações da teoria (eg., MORI, 2013). A obra Pensamento e Linguagem, por exemplo, deveria ter sido traduzida como Pensamento e Fala, ou mais precisamente, Pensar e Falar ${ }^{3}$. Este problema foi corrigido nos Estados Unidos no final da década de 80 (VYGOTSKY, 1987). Infelizmente, no Brasil, essa obra foi recentemente traduzida do russo para o por-

\footnotetext{
${ }^{2}$ No Brasil, esta afirmação não é verdadeira para as pesquisas desenvolvidas na área de Educação. Para uma apresentação rigorosa, porém acessível das ideias de Vygotsky, dirigida ao público geral, ver (REGO, 2010). Para uma discussão mais específica de vários pontos da abordagem vygotskiana, ver (PINO, 2000).

3 Na monografia Myshlenie $i$ Rich', traduzida originalmente como Thought and Language (Pensamento e Linguagem), "rich" significa "speech" (fala), ao passo que "language", em russo, se escreve "yazyk". De modo similar, há uma distinção entre as palavras "Myshlenie" e "Mysl". Em russo, Mysl significa thought (pensamento enquanto conteúdo das ideias), ao passo que Myshlenie significa thinking (pensamento enquanto ato de pensar).
} 
tuguês sob o título A Construção do Pensamento e da Linguagem (VIGOTSKI, 2001).

Outro problema, de ordem mais ideológica, tem sido a supressão de partes dos textos de Vygotsky durante a guerra fria. De acordo com a tradutora da edição francesa de Pensamento e Linguagem, a tradução norte-americana reduziu dois terços do texto original, retirando passagens essenciais por fazer referência ao marxismo (LIMA, 1990).

Um terceiro problema ainda mais sério, mas que está diretamente ligado aos anteriores, é a incompatibilidade entre as visões de mundo do Ocidente e da antiga União Soviética acerca do funcionamento mental humano. Essas visões diferem principalmente em seus pressupostos acerca do papel das forças sociais na formação do indivíduo (WERTSCH, 1985). Ao ignorar este fato, muitos dos conceitos vygotskianos acabam sendo mal interpretados quando são transferidos inadvertidamente de uma tradição de pesquisa para outra. A respeito desse fato, Wertsch prestou o seguinte depoimento no prefácio da edição castelhana de sua obra Mind as Action.

Cheguei lá [em Moscou] como um típico "Ph.D." nos anos setenta. Eu estava interessado em saber o que estava acontecendo na União Soviética, especialmente na tradição de L. S. Vygotsky, mas eu encarei essa tarefa a partir da perspectiva que havia sido socializada nos Estados Unidos. Eu ainda me lembro que a primeira coisa que eu pensei foi que eu entendia o que era dito nas conferências e na literatura, e que era como se fazia nos Estados Unidos... só que muito antes. Porém, alguns meses mais tarde, eu comecei a duvidar dessa interpretação quando comecei a ter cada vez menos sucesso nas minhas tentativas de assimilar as ideias que eu encontrava ao quadro teórico que eu trazia... Os problemas que se consideravam relevantes eram simplesmente diferentes daqueles que eu havia enfrentado nos Estados Unidos, assim como as formas de raciocínio e as evidências que se consideravam convincentes. Toda esta forma de falar e de pensar sobre os problemas [...] era nova para mim, e eu precisei de tempo para reconhecê-la e, obviamente, para dominá-la (WERTSCH, 1999, p. 11).

Para entender a essência da abordagem vygotskiana é preciso reconhecer que Vygotsky foi fruto do contexto social e cultural de sua época. Assim como os demais psicólogos soviéticos da década de 20, Vygotsky estava interessado em estabelecer as bases para a construção de uma psicologia essencialmente marxista, 
fundamentada nos princípios do materialismo histórico e dialético ${ }^{4}$. Assim, é natural que suas ideias se distanciem das teorias cognitivas, que formam a base da psicologia contemporânea.

Apesar disso, é muito comum encontrarmos trabalhos que apostam em uma articulação teórica entre Vygotsky e autores cognitivistas, tais como David Ausubel. Há ainda aqueles que classificam Vygotsky como sendo ele próprio um cognitivista (MOREIRA, 1999). Essa leitura equivocada tem levado à banalização de vários conceitos importantes da teoria de Vygotsky tais como "desenvolvimento", "mediação", "interação social", "internalização" e "zona de desenvolvimento proximal".

Entre os erros mais comuns encontrados na literatura, destacam-se: (a) a interação social como negociação de significados ${ }^{5}$; (b) a noção de professor como mediador do conhecimento; (c) a noção de livro didático como parceiro mais capaz; (d) o desenvolvimento como a construção de novas estruturas cognitivas. Todas estas noções incorporam o que se conhece hoje como a "metáfora da aquisição" (SFARD, 1998). De acordo com esta metáfora, o conhecimento é "algo dentro da cabeça". Uma vez adquirido, o conhecimento pode ser aplicado, transferido para outras situações e compartilhado com outros sujeitos.

É preciso reconhecer que para apreciar as ideias de Vygotsky, o leitor deverá se desprender de determinados pressupostos cognitivistas (ou até mesmo intuitivos) sobre o funcionamento da mente humana, da mesma forma que um iniciante no estudo da Física deverá se libertar de certos pressupostos clássicos (ou até mesmo intuitivos) se quiser entender a teoria da relatividade ou a mecânica quântica. De certo modo, o entendimento da teoria de Vygotsky requer uma mudança conceitual (no sentido cognitivista) ou, mais precisamente, uma "virada sociocultural".

Para apresentar as ideias de Vygotsky, Wertsch $(1985,1991)$ as organizou a partir de três temas gerais: (1) a confiança na análise genética ou desenvolvimen-

\footnotetext{
${ }^{4}$ Renomados pesquisadores do ensino de física, no Brasil, têm subestimado o papel do marxismo no pensamento de Vygotsky, provavelmente em virtude da conotação "panfletária" que é comumente atribuída a este termo. Para uma discussão da influência marxista em Vygotsky, ver Lima Junior; Ostermann; Rezende (2012).

Essa noção é particularmente problemática porque ela incorpora aquilo que podemos chamar de "pressuposto da verificação". Esta formulação simplifica a noção de interação social ao assumir que a mesma serve apenas para o indivíduo se assegurar de que os significados por ele captados (em um livro, por exemplo) são os mesmos compartilhados socialmente.
} 
tal; (2) a tese de que as funções mentais superiores, no indivíduo, derivam da vida social; (3) a tese de que a atividade humana, tanto no plano social como no plano individual, é mediada por instrumentos e signos. Apesar de a nossa apresentação não seguir exatamente essa mesma ordem, muito do que será exposto, a seguir, está diretamente relacionado com esses três temas gerais.

\section{A mediação na abordagem vygotskiana}

Um ponto de partida para se apreciar o brilhantismo das ideias de Vygotsky é a distinção comumente feita entre os processos psicológicos elementares e as funções psicológicas superiores ${ }^{6}$ (VYGOTSKY, 1994). Tal distinção tem uma longa história na psicologia, surgindo da necessidade de separar fenômenos psicológicos que podem ser encontrados tanto em seres humanos como em animais daqueles que são exclusivamente humanos (COLE, 1985).

É importante frisar que o termo "função" é compatível com a noção de "ação", que se tornou o grande foco das pesquisas desenvolvidas na antiga União Soviética $^{7}$ (ZINCHENKO, 1985). Tendo em vista a descrição dos fenômenos psicológicos em termos de funções mentais (qual a função da mente?), fica claro que Vygotsky estava primeiramente interessado na análise do indivíduo em "atividade prática" (lembrar, raciocinar, etc.), e não em entidades cognitivas abstratas tais como "esquemas", "modelos mentais" e outros construtos da psicologia contemporânea que supostamente existem "dentro da cabeça" do indivíduo, independentemente da prática humana. Nesta perspectiva, é preferível falar em lembrar ou raciocinar como algo que se "faz" do que falar em memória ou raciocínio como algo que se "tem".

Tendo feito tal observação, voltemos agora à distinção entre as funções mentais elementares e as superiores. Para Vygotsky, as formas superiores (tipicamente humanas) de funcionamento mental são definidas como sendo aquelas que envolvem mediação.

\footnotetext{
"De acordo com Wertsch (1985), "psychic" (psíquico) é a tradução mais literal da palavra "psikhicheskii", embora ele prefira usar o termo "mental" devido à conotação inadequada que a palavra psychic tem na língua inglesa. Segundo este autor, os psicólogos russos tendem a usar o termo "psikhologicheskii" (psicológico) para ser referir à "ciência da mente" e psikhicheskii para se referir ao "objeto de estudo" da psicologia.

${ }^{7}$ Vladimir Zinchenko (1985) afirma que a ação - e não o "significado da palavra" como o próprio Vygotsky (1987) havia assinalado - é a unidade de análise mais adequada para o referencial vygotskiano.
} 
As funções elementares têm como característica fundamental o fato de serem total e diretamente determinadas pela estimulação ambiental. No caso das funções superiores, a característica essencial é a estimulação autogera$d a$, isto é, a criação e o uso de estímulos artificiais que se tornam a causa imediata do comportamento (VYGOTSKY, 1994, p. 53).

Usando a memória como exemplo, Vygotsky propôs uma distinção entre memória natural e memória indireta.

[A memória natural] caracteriza-se pela impressão não mediada de materiais, pela retenção de experiências reais como a base dos traços mnemônicos (de memória) [...] Esse tipo de memória é bastante próximo da percepção, uma vez que ele surge da influência direta de estímulos externos sobre os seres humanos (VYGOTSKY, 1994, p. 52).

Com relação à memória indireta (mediada), Vygotsky escreveu.

Mesmo essas operações relativamente simples, como atar nós e marcar um pedaço de madeira com a finalidade de auxiliares mnemônicos, modificam a estrutura psicológica do processo de memória. Elas estendem a operação de memória para além das dimensões biológicas do sistema nervoso humano, permitindo incorporar a ele estímulos artificiais, ou autogerados, que chamamos de signos (VYGOTSKY, 1994, p. 38).

De acordo com a citação acima, as formas superiores de memória resultam não apenas do desenvolvimento de constituições mentais e nervosas vinculadas ao processo de memória, mas, sobretudo, do desenvolvimento de um método de memorização baseado no uso de signos. É precisamente no uso mediado de meios externos ao corpo humano que se define a natureza "distribuída" da atividade mental ${ }^{8}$. Este é um dos sentidos no qual a mente pode ser entendida como algo que "se estende além da pele" (WERTSCH, 1991).

Vejamos um exemplo contemporâneo: um estudante de Física combinou de emprestar um livro para um colega, no entanto, ao sair de casa, ele esqueceu de levar o livro consigo. Somente após encontrar o colega na sala de aula é que o estudante lembrou que deveria ter colocado o livro na mochila. Este é claramente um caso de memória natural, uma vez que foi a estimulação visual do colega que

8 "Cognição distribuída" é um termo cunhado na ciência cognitiva contemporânea por Edwin Hutchins (1995) para descrever sistemas que envolvem a coordenação de indivíduos, artefatos e o ambiente. Para uma discussão sobre a distribuição social da mente em uma aula de física quântica, ver Pereira, Ostermann e Cavalcanti (2012). 
causou a lembrança no estudante. Ele não teve controle algum sobre sua memória; a imagem do livro simplesmente apareceu em sua mente.

No dia seguinte, no entanto, ele resolveu colocar um lembrete no seu telefone celular, programando-o para despertar minutos antes de ele sair de casa. Ao ouvir o toque do celular, ele se lembrou de colocar o livro na mochila, podendo assim emprestar o livro para o colega. Neste segundo caso, a memória também foi o resultado de uma estimulação externa (toque do celular). No entanto, há uma diferença crucial: a lembrança do livro resultou de um ato intencional. Através do uso do celular (mediação), o estudante passou a ter controle sobre sua própria memória. Controle não apenas do objeto a ser lembrado (livro), mas inclusive do instante exato de sua manifestação (minutos antes de sair de casa).

Assim, os signos servem como meios auxiliares para os seres humanos influenciarem o próprio comportamento, assim como o comportamento de outros seres humanos (considere o caso alternativo, no qual o colega envia uma mensagem de texto para o estudante, minutos antes de ele sair de casa, lembrando-o de levar o livro). Este nível de controle dos fenômenos psicológicos, baseado no uso de signos, é uma característica exclusiva da atividade humana.

Para Vygotsky, a invenção e o uso de signos como meios auxiliares para solucionar problemas psicológicos (lembrar, raciocinar, comparar coisas, etc.) é análoga à invenção e ao uso de instrumentos, só que agora no plano psicológico (VYGOTSKY, 1994, p. 52). Nesse sentido, os signos podem ser justificadamente chamados de "ferramentas psicológicas". Como exemplos de ferramenta psicológica, Vygotsky citou: "a linguagem, as diferentes formas de numeração e cálculo, os dispositivos mnemotécnicos, o simbolismo algébrico, as obras de arte, a escrita, os diagramas, os mapas, os desenhos, todo tipo designo convencional etc." (VIGOTSKI, 2004, p. 93).

É importante destacar que os signos não facilitam simplesmente uma função mental pré-existente, enquanto as deixam qualitativamente inalterada. Pelo contrário, a introdução do signo na atividade psicológica causa uma transformação fundamental na função mental (considere, por exemplo, o surgimento de novas habilidades e estratégias mentais associadas ao uso do Google e de outros sites da internet).

Outra importante característica do signo é sua natureza social. De acordo Vygotsky, os signos "são criações artificiais; estruturalmente, são dispositivos sociais e não orgânicos ou individuais" (VIGOTSKI, 2004, p. 93). Isto significa que os signos são dispositivos tipicamente usados na interação social (só mais tarde eles se tornam um meio de controle do próprio comportamento). Além disso, os signos são o produto do desenvolvimento histórico, no sentido de que eles não 
são inventados por cada indivíduo que os utilizam, nem são descobertos na interação independente dos indivíduos com a natureza. Ao contrário, eles são parte do contexto social e cultural em que os indivíduos estão imersos.

Assim, não faz sentido em falar que o professor é o "mediador" do conhecimento. Na perspectiva vygotskiana, mediação é um termo designado para caracterizar o uso de meios auxiliares na solução de problemas psicológicos (lembrar, raciocinar, etc.). Usamos calendários como meios auxiliares para planejar uma viagem ou uma reunião. Usamos o despertador para acordar pela manhã e o relógio para sincronizar ou para medir a duração de certos eventos. Usamos palavras para pensar e a fala para orientar o pensamento de outros. O fato é que muito dessas atividades são quase impossíveis de se realizar sem o uso adequado de signos. Em suma, o professor não pode ser um "mediador", pois ele em si não é um signo! Trata-se sim de um agente ativo que também utiliza mediação na realização de atividades práticas.

\section{A formação social da mente: o papel da interação social}

Uma das teses mais importantes de Vygotsky é a afirmação de que as funções mentais superiores, no indivíduo, derivam da vida social. Essa tese aparece formulada na sua famosa "lei genética geral do desenvolvimento cultural", enunciada no texto The genesis of higher mental function (VYGOTSKY, 1981). Uma versão simplificada desta lei pode ser encontrada no capítulo 4 de $A$ formação social da mente.

Todas as funções no desenvolvimento da criança aparecem duas vezes: primeiro, no nível social, e, depois, no nível individual; primeiro, entre pessoas (interpsicológica), e, depois, no interior da criança (intrapsicológica). Isso se aplica igualmente para a atenção voluntária, para a memória lógica e para a formação de conceitos. Todas as funções superiores originam-se das relações reais entre indivíduos humanos (VYGOTSKY, 1994, p. 75).

$\mathrm{O}$ enunciado acima expressa duas ideias que não costumam ser muito bem entendidas no contexto do ensino de Física. A noção de função mental superior envolvida neste enunciado é radicalmente diferente daquilo que os pesquisadores normalmente têm em mente quando usam este termo. Em primeiro lugar, este enunciado afirma que termos como "memória", "atenção voluntária", e "formação de conceitos" podem ser apropriadamente aplicados tanto a grupos como a indivíduos. Para ilustrar o tipo de fenômeno que Vygotsky parecia ter em mente, considere o seguinte exemplo. 
Uma criança de 6 anos de idade perdeu um brinquedo e pede ajuda ao seu pai. O pai pergunta onde ela viu o brinquedo pela última vez; a criança responde "não consigo lembrar". Ele faz uma série de perguntas - não está em seu quarto? Lá fora? No vizinho? Para cada pergunta, a criança responde "não". Quando ele diz "no carro?", ela responde "acho que sim" e sai para reaver seu brinquedo (THARP; GALLIMORE, 1988, p. 14).

Uma importante questão que surge desse exemplo é: "quem lembrou onde estava o brinquedo?". Neste caso, não é possível responder a tal pergunta apontando um ou outro indivíduo isoladamente. A dupla enquanto um "sistema colaborativo" realizou a função de lembrar no plano social (WERTSCH, 1991). Esta mesma linha de raciocínio pode ser estendida até outros aspectos do funcionamento mental humano tais como o pensamento dedutivo ou a resolução de problemas. Este exemplo representa um segundo sentido no qual a mente pode ser entendida como algo que "se estende além da pele".

A segunda afirmação básica que deriva da lei genética geral do desenvolvimento cultural é a origem social das funções superiores. De acordo com esta afirmação, as funções mentais superiores surgem "primeiro, entre pessoas".

Qualquer função mental superior foi externa porque ela foi social em algum ponto antes de se tornar uma função interna, verdadeiramente mental. Ela foi antes uma relação social entre duas pessoas. Os meios de se influenciar alguém foram originalmente meios de influenciar outros ou meios de outros influenciarem um indivíduo (VYGOTSKY, 1981, p. 162).

Obviamente, toda atividade conduzida no plano social é sempre mediada por signos. É neste sentido que afirmamos anteriormente que o signo é um meio de interação social e apenas mais tarde se torna um meio de controle do próprio comportamento. Assim, tudo aquilo que conseguimos realizar mentalmente, com o auxílio de signos, foi, em algum estágio do nosso desenvolvimento, realizado em colaboração com outros, através da interação social. Mesmo no caso do autodidata, que aprende algo por si próprio lendo um livro, por exemplo, a própria leitura e interpretação do texto são formas de ação mental que foram conduzidas com a ajuda de outros durante o seu processo de alfabetização. Nesse sentido, a metáfora da aquisição dá lugar à "metáfora da participação" (SFARD, 1998).

A transferência da atividade externa para o plano interior (como a fala social que se transforma em pensamento) é normalmente descrita em termos da noção de "internalização" (VYGOTSKY, 1994), que nada tem a ver com o ato de 
criar representações mentais de um objeto externo. A internalização é a reconstrução interna (mental) de uma operação externa: "todas as funções mentais superiores são relações sociais internalizadas" (VYGOTSKY, 1981). É importante destacar que a internalização não é a transferência da atividade externa para um plano de consciência interno, pré-existente. De acordo com Leontiev, ela representa "o processo no qual este plano interno é formado" (LEONT'EV, 1981). Isto significa que o título da obra $A$ formação social da mente deve ser interpretado de maneira literal! (a mente se forma na interação social).

Toda esta forma de conceber o papel da interação social na formação do sujeito implica uma estratégia analítica que parece paradoxal à primeira vista, mas que convida o pesquisador a começar a análise do funcionamento mental do indivíduo indo além (para fora) do próprio indivíduo. Isso não quer dizer que as funções superiores no indivíduo sejam uma simples cópia de processos socialmente organizados. Conforme o próprio Vygotsky alertou, a "internalização transforma o processo em si e muda sua estrutura e suas funções" (VYGOTSKY, 1981).

Essas noções sobre as origens sociais das funções superiores se encontram articuladas ao ensino através da noção de zona de desenvolvimento proximal, definido como sendo:

a distância entre o nível de desenvolvimento real, que se costuma determinar através da solução independente de problemas, e o nível de desenvolvimento potencial, determinado através da solução de problemas sob a orientação de um adulto ou em colaboração com parceiros mais capazes (VYGOTSKY, 1994, p. 112).

Daí segue a ideia de que o bom ensino é aquele que se coloca à frente do desenvolvimento, centrando-se em tarefas que os indivíduos apenas dominam parcialmente, mas que são capazes de participar de sua execução mediante a assistência e a supervisão do professor.

É importante salientar que, na visão vygotskiana, interação social significa atividade envolvendo pelo menos dois indivíduos (um adulto e uma criança, por exemplo). Diferentemente do que muitos pensam, não é necessário que haja um intenso diálogo entre as partes - algo que poderia ser classificado como "abordagem comunicativa interativa" (MORTIMER; SCOTT, 2002). Mesmo nos casos em que o professor resolve um problema de Física no quadro negro e os alunos apenas copiam silenciosamente, há interação social. Neste caso, o objetivo do professor não é encontrar a "resposta correta", mas sim resolver o problema no plano interpsicológico, para que os alunos possam, futuramente, internalizar os padrões de 
solução utilizados. O modo como o professor orienta a ação do aluno será o modo como o aluno orientará, no futuro, a sua própria ação.

A partir da lei genética geral do desenvolvimento cultural, fica claro que o papel da interação social não é assegurar que os sujeitos verifiquem se os significados captados por eles em um livro são os mesmos compartilhados socialmente. É muito mais que isso! Através da interação social, os sujeitos criam novas habilidades mentais; habilidades estas que estão associadas ao uso de novos meios auxiliares. O uso concreto de novas formas de mediação sempre se dá em atividades externas, conduzidas no plano intermental (entre pessoas). Assim, fica claro também o papel desempenhado pelo livro didático no processo de internalização. Sendo ele próprio um artefato (e não uma pessoa), dificilmente o livro didático poderá exercer o papel de parceiro mais capaz, que dá suporte e supervisiona a atividade, embora ele represente uma poderosa ferramenta psicológica (isto é, uma forma de mediação).

\section{O desenvolvimento das funções mentais superiores}

Um terceiro tema geral que perpassa todos os textos de Vygotsky é o uso do método genético ou evolutivo. O termo genético se refere a processos de desenvolvimento e nada tem a ver com genes, código genético ou outros termos da biologia (WERTSCH, 1985). Apesar do emprego deste método, a teoria de Vygotsky não deve ser confundida com as teorias tradicionais da psicologia do desenvolvimento, que têm origem na proposta de Piaget. Atualmente, o termo "psicologia do desenvolvimento" tem sido usado quase que exclusivamente para se referir ao desenvolvimento psicológico ao longo da vida de um indivíduo (linha ontogenética), principalmente nos períodos da infância e da adolescência (WERTSCH, 1996). Já a teoria de Vygotsky identifica outras duas linhas principais de desenvolvimento, relativas à evolução biológica da espécie humana (linha evolutiva) e ao desenvolvimento histórico da humanidade (linha histórica) (VYGOTSKY; LURIA, 1996).

O método genético é motivado pelo pressuposto de que só é possível entender muitos aspectos da mente humana recorrendo-se às suas origens e às transições pelas quais ela tem passado (WERTSCH, 1991). Nesta perspectiva, o estudo da natureza dos processos psicológicos a partir da análise dos produtos estáticos do desenvolvimento pode acabar comprometido pelo surgimento de formas "fossilizadas" de comportamento, isto é, de funções automatizadas que, devido às suas origens remotas, estão agora sendo repetidos pela enésima vez e tornaram-se mecanizadas (VYGOTSKY, 1994). 
Um exemplo disso é a nossa capacidade de multiplicar "de cabeça" algarismos simples como 3 e 4, por exemplo. Considere o caso de um professor que pergunta em sala de aula "quanto é três vezes quatro?" e ouve de um aluno a resposta "doze!". A simples resposta nada nos revela sobre o processo que levou o aluno ao resultado dado. Com base na observação, podemos apenas enumerar as características externas deste processo (o tempo de reação do aluno, se a resposta está correta ou não, etc.), fornecendo assim uma mera análise fenotípica (descrição) do mesmo.

Se voltarmos às origens deste processo e observarmos o modo como crianças pequenas passam a dominar a multiplicação (isto é, sua base dinâmica causal), presenciaremos o desenvolvimento de um método baseado no uso de signos. Inicialmente, a criança aprende a multiplicar formando conjuntos com igual número de elementos (por exemplo, três grupos de quadro blocos) para depois somar o número total de elementos. Mais tarde, a criança passa a utilizar a tabuada para obter o resultado de certas multiplicações. Em um estágio inicial deste processo, a criança só consegue fornecer o resultado correto de uma multiplicação mediante o uso da tabuada. Com o tempo, após um longo processo de repetição, estas operações se tornam mecanizadas, dando a falsa impressão de não serem mediadas.

Este tipo de análise, que retorna à origem do processo e revela suas relações dinâmicas reais ao invés de enumerar suas características externas, Vygotsky (1994) chamou de análise genotípica (explicação). É por isso que a maioria dos estudos empíricos de Vygotsky envolvia crianças. Sua intenção era mapeara origem de certas funções superiores para entender a sua dinâmica. Os pontos de "viragem" no desenvolvimento mental da criança estão associados ao domínio (internalização) de novas formas de mediação. A partir deste exemplo, podemos inferir que quando uma função mental parece não envolver mediação, há apenas duas explicações possíveis: (a) ou trata-se de uma função elementar, comum a outros animais (não humanos); (b) ou trata-se de uma função superior fossilizada.

O método genético de Vygotsky pode ser resumido da seguinte maneira [1]: todas as funções mentais superiores devem ser estudadas utilizando-se a análise genotípica; o desenvolvimento das funções mentais superiores deve ser descrito tanto em termos de mudanças qualitativas (radicais) quanto em termos de incrementos quantitativos; os principais pontos de "viragem" no desenvolvimento envolvem mudanças nas formas de mediação utilizadas; o entendimento completo dos processos psicológicos requer o exame de várias linhas de desenvolvimento (evolutiva, histórica e ontogenética), cada qual governado por um conjunto próprio de princípios explicativos. 
A partir do método genético, fica claro que a teoria de Vygotsky não deve ser equiparada com as demais teorias da psicologia do desenvolvimento. Sua análise não está centrada no desenvolvimento de "estruturas cognitivas" ou de qualquer outra entidade abstrata, que supostamente existem dentro da cabeça do indivíduo, mais sim no desenvolvimento das funções mentais superiores que, por definição, são formas tipicamente humanas de ação mental que têm como base o "uso de signos". A partir da perspectiva vygotskiana, o desenvolvimento humano representa a "história natural das operações com signos" (VYGOTSKY, 1994).

\section{Vygotsky e o Ensino de Física}

Uma implicação da abordagem vygotskiana para o ensino de Física é afirmação de que a introdução de um novo signo na atividade psicológica causa uma transformação fundamental das funções mentais superiores. Um novo texto de apoio, um experimento didático, uma simulação computacional, entre outras inovações, têm o potencial de causar mudanças significativas no modo como os estudantes realizam determinadas atividades mentais, ou, ainda, propiciar aos estudantes uma forma de realizar certas atividades mentais que não poderiam ser realizadas sem o auxílio do signo em questão. Aprender a lidar com um conjunto de dados de uma observação experimental empregando uma técnica particular de construção de gráficos ajuda o estudantes a perceber certos padrões de comportamento do sistema observado que não poderiam ser revelados a partir do uso de outro modo de mediação (como uma equação, por exemplo). A ideia básica é que novas ferramentas psicológicas proporcionam novas possibilidades para o estudante.

Para que isso ocorra, no entanto, é necessário que o estudante passe a dominar a atividade tendo como base o uso do novo signo. Para isso, é necessário que tal atividade seja conduzida no plano interpsicológico da sala de aula, levando o aluno a realizar atividades em colaboração com outros sujeitos tais como o professor ou colegas mais experientes (em atividades em grupo). Como as formas superiores de função mental são relações sociais internalizadas, mudanças na organização de processos sociais levam a mudanças na organização do funcionamento psicológico individual. Atribuir ao aluno um papel mais ativo nas atividades desenvolvidas no contexto da sala de aula, a exemplo da aprendizagem baseada em investigação (inquiry-based learning), pode levá-lo ao desenvolvimento da autonomia.

Em suma, para compreender o desenvolvimento mental individual é necessário examinar os padrões específicos das interações sociais nas quais o indivíduo participa. Nesse sentido é mais interessante centrar-se mais no processo da 
aprendizagem no que no seu produto final. Ao invés de avaliar o potencial de produtos educacionais tais como textos de apoio, simulações computacionais e atividades experimentais a partir de metodologias baseadas em pré e pós-testes, outra possibilidade, bastante praticada nas pesquisas em ensino de ciências, é a análise das atividades conduzidas no plano social da sala de aula (através da gravação em vídeo, por exemplo). Que ações do professor dão mais suporte à atividade realizada pelo aluno? Como cada aluno contribui para a realização da tarefa como um todo? De que forma as novas ferramentas psicológicas, introduzidas em sala de aula, possibilitam novas habilidades mentais? Questões como essas poderiam constituir uma agenda para pesquisas fundamentadas na abordagem vygotskiana.

\section{Considerações Finais}

A partir das ideias discutidas neste artigo, é possível apreciar como a teoria de Vygotsky difere radicalmente das demais teorias cognitivas usadas no ensino de Física. Seu compromisso com o marxismo o levou a incorporar a noção de mediação aos estudos da psicologia humana, tornando esta disciplina uma ciência concreta. A ênfase na análise do sujeito em atividade prática (em detrimento da análise de entidades cognitivas abstratas) representa uma verdadeira revolução na forma de conceber o funcionamento humano que tem sido negligenciada no ensino de Física devido à pobre tradução de obras como Pensamento e Linguagem. Na perspectiva vygotskiana, a "linguagem" é uma mera abstração. Concretamente, o que existe é a fala, a escrita e o pensamento (verbal). Mesmo quando o foco recai sobre a aprendizagem conceitual, a mesma deve ser entendida mais em termos do "domínio" (WERTSCH, 1993) e "uso" de conceitos (WELLS, 2008) e não em termos de sua aquisição.

É importante destacar que o nosso objetivo aqui não é fornecer uma descrição completa da teoria de Vygotsky, mas sim de apresentar alguns pontos que consideramos radicalmente diferentes da proposta cognitivista e que têm sido ignorados nas pesquisas em ensino de Física. Estamos cientes de que nossa apresentação é uma simplificação de uma abordagem muito mais complexa e cheia de nuanças. Nesse sentido, vários outros conceitos importantes da abordagem vygotskiana não foram contemplados em nossa discussão. Além disso, cabe frisar que a perspectiva wertschiana na qual nos baseamos para escrever este texto não é a única possível e que vários outros teóricos especialistas em Vygotsky discordam desta interpretação em diversos pontos. No entanto, todos eles, cada um a sua maneira, apresenta uma visão que contrasta fortemente com as teorias cognitivistas utilizadas no ensino de Física. Ao que parece, a tradução direta do russo para o português 
das obras de Vygotsky não é suficiente para informar os pesquisadores da área sobre a verdadeira "essência" da abordagem vygotskiana. Para isso, é necessária a consulta a fontes secundárias, fornecidas principalmente por teóricos da terceira geração da tradição vygotskiana que foram formados em contato direto com autores da segunda geração, tais como Davidov, Leontiev, Luria, Zinchenko, entre outros. Este artigo representa somente uma introdução a essa "nova" visão.

\section{Referências}

COLE, M. The zone of proximal development: Where culture and cognition create each other. In: WERTSCH, J. V. Culture, communication, and cognition: Vygotskian perspectives. New York: Cambridge University Press, 1985. p. 146161.

ENGESTRÖM, Y. Activity theory and individual and social transformation. In: ENGESTRÖM, Y.; MIETTINEN, R.; PUNAMÄKI, R. Perspectives on activity theory. New York: Cambridge University Press, 1999.

HUTCHINS, E. How a Cockpit Remembers Its Speeds. Cognitive Science, v. 19, n. 3, p. 265-288, 1995.

LEONT'EV, A. N. The problem of activity in psychology. In: WERTSCH, J. V. The concept of activity in Soviet psychology. Armonk: Sharpe, 1981. p. 37-71.

LIMA, E. A. S. O conhecimento psicológico e suas relações coma educação. Em Aberto, Brasília, ano 9, n. 3, p. 3-24, out. nov. 1990.

LIMA JUNIOR, P; OSTERMANN, F.; REZENDE, F. Marxism in Vygotskian approaches to cultural studies of science education. Cultural Studies of Science Education. No prelo.

MOREIRA, M. A. Teorias de Aprendizagem. São Paulo: Editora Pedagógica e Universitária, 1999.

MORI, R. C. A psicologia histórico-cultural nos artigos publicados em 'Química Nova na Escola'. In: ENCONTRO NACIONAL DE PESQUISA EM EDUCAÇÃO EM CIÊNCIAS, 9., 2013, Águas de Lindóia. Atas... Rio de Janeiro: ABRAPEC, 2013. p. 1-8.

MORTIMER, E. F.; SCOTT, P. Atividade discursiva nas salas de aula de ciências: uma ferramenta sociocultural para analisar e planejar o ensino. Investigações em Ensino de Ciências, Porto Alegre, v. 7, n. 3, p. 283-306, 2002.

PEREIRA, A. P.; OSTERMANN, F.; CAVALCANTI, C. J. H. Um exemplo de "distribuição social da mente" em uma aula de Física quântica. Ciência \& Educação, Bauru, v. 18, n. 2, p. 257-270, 2012. 
PINO, A. (Org.). Editorial. Educação e Sociedade, Campinas, v. 21, n. 71, p. 7 17, jul. 2000.

REGO, T. C. (Org.). Educação: História da pedagogia 2 - Lev Vigostski. São Paulo: Editora Segmento, 2010.

SFARD, A. On two metaphors for learning and the danger of choosing just one. Educational Researcher, Washington DC, v. 27, n. 2, p. 4-14, 1998.

THARP, R. G.; GALLIMORE, R. Rousing minds to life: Teaching, learning, and schooling in social context. New York: Cambridge University Press, 1988.

VIGOTSKI, L. S. A construção do pensamento e da linguagem. São Paulo: Martins Fontes, 2001.

VIGOTSKI. L. S. O método instrumental em psicologia: In Teoria e método em psicologia. 3. ed. São Paulo: Martins Fontes, 2004. p. 93-102.

VYGOTSKY, L. S. The genesis of higher mental functions. In: WERTSCH, J. V. The concept of activity in Soviet psychology. Armonk: Sharpe, 1981. p. 144-188.

VYGOTSKY, L. S. The collected works of L. S. Vygotsky. New York: Plenum Press, 1987.

VYGOTSKY, L. S. A formação social da mente: o desenvolvimento dos processos psicológicos superiores. 5. ed. São Paulo: Martins Fontes, 1994.

VYGOTSKY, L. S.; LURIA, A. R. Estudos sobre a história do comportamento: o macaco, o primitivo e a criança. Porto Alegre: Artmed, 1996.

WELLS, G. Forum: Learning to use scientific concepts. Cultural Studies of Science Education, New York, v. 3, n. 2, p. 329-350, 2008.

WERTSCH, J. V. From social interaction to higher psychological processes: A clarification and application of Vygotsky's theory. Human Development, Berkley, v. 22, n. 1, p. 1-22, 1979.

WERTSCH, J. V. Vygotsky and the social formation of mind. Cambridge: Harvard University Press, 1985.

WERTSCH, J. V. Voices of mind: A sociocultural approach to mediated action. Cambridge: Harvard University Press, 1991.

WERTSCH, J. V. Commentary on J. A. Lawrence and J. Valsiner "Conceptual roots of internalization: from transmission to transformation". Human Development, Berkley, v. 36, n. 3, p. 168-171, 1993.

WERTSCH, J. V. Introdução. In: VYGOTSKY, L. S.; LURIA, A. R. Estudos sobre a história do comportamento: o macaco, o primitivo e a criança. Porto Alegre: Artmed, 1996. p. 9-13. 
WERTSCH, J. V. La mente en acción. Buenos Aires: Aique, 1999.

WERTSCH, J. V.; DEL RÍO, P.; ALVAREZ, A. Estudos socioculturais: história, ação e mediação. In: __ Estudos socioculturais da mente. Porto Alegre: Artemed, 1998. p. 11-38.

WERTSCH, J. V.; TULVISTE, P. L. L. S. Vygotsky and contemporary developmental. Developmental Psychology, Washington DC, v. 28, n. 4, p. 548-557, jul. 1992.

ZINCHENKO, V. P. Vygotsky's ideas about units for the analysis of mind. In: WERTSCH, J. V. Culture, communication, and cognition: Vygotskian perspectives. New York: Cambridge University Press, 1985. p. 94-118.

ZINCHENKO, V. P. A psicologia histórico-cultural e a teoria psicológica da atividade: retrospectos e prospectos. In: WERTSCH, J. V; DEL RÍO, P.; ALVAREZ, A. Estudos socioculturais da mente. Porto Alegre: Artmed, 1998. p. 41. 